\title{
Practicalities of health survey fieldwork research in a resource limited setting: challenges and lessons learnt from Uganda.
}

\author{
Julie Abimanyi-Ochom
}

Centre for Population Health Research-Deakin Health Economics, Deakin University, 221 Burwood Highway, Burwood, Victoria, 3125 Australia.

\begin{abstract}
Background: Countless research has been undertaken in sub-Saharan African countries to provide evidence for health policy interventions. However, despite the bulk of health research, very few studies have documented the experiences and practicalities of conducting health survey fieldwork in such settings.

Methods: Results were obtained through synthesis of notes on fieldwork experiences documented during a household survey as part of a doctoral research project. Challenges faced and adaptive strategies developed to overcome or reduce the impact on the survey are highlighted.

Results: Key challenges included infrastructure and electrical power outages; sampling and access to clients; ethics approval and political stability; and safety and wellbeing of researchers. Adaptive strategies were developed to overcome the different challenges faced.

Conclusion: The experiences highlighted and strategies developed to overcome fieldwork challenges give practical advice for future data collection research in similar sub-Saharan African settings.

Keywords: Health survey fieldwork, resource limited setting, sub-Saharan Africa, fieldwork challenges, lessons learnt.

DOI: https://dx.doi.org/10.4314/ahs.v17i1.34

Cite as: Abimanyi-Ochom J. Practicalities of health survey field work research in a resource limited setting: challenges and adaptive strategies learnt from Uganda. Afri Health Sci. 2017;17(1): 278-284. https://dx.doi.org/10.4314/abs.v17i1.34
\end{abstract}

\section{Background}

Countless health research surveys have been undertaken in resource limited settings especially in the sub-Saharan African (SSA)region ${ }^{1-3}$. In the majority of cases, these surveys have involved face-to-face interviews at the health unit, household or individual level ${ }^{4-6}$. In contrast, health research surveys in developed countries tremendously use internet, postal and telephone survey techniques ${ }^{7-9}$. These survey modalities are not readily available in SSA due to poor telecommunication and energy infrastructure and the relatively high cost of access to these services ${ }^{10}$ 11. In cases when used, such survey modalities are likely to lead to response bias towards urban populations and the more literate ${ }^{11-14}$. Consequently, a majority of health
Corresponding author:
Julie Abimanyi-Ochom, Centre for Population Health Research-Deakin Health Economics, Deakin University, 221 Burwood Highway, Burwood, Victoria, 3125 Australia. Phone: +61 392517772
Email: j.abimanyiochom@deakin.edu.au

research surveys in SSA comprise of face-to-face interviews that may require translation and observation.

Most health data for research in SSA are collected at the health facility level through focus group discussions, indepth interviews, exit interviews and surveillance. These include large scale routine health surveys such as the demographic and heath survey (DHS) and the living standards measurement survey (LSMS). An additional layer of complexity exists when surveys are undertaken at the household level, where challenges exist due to the extensive nature of coverage compared to facility-based surveys. Both the DHS and the LSMS also collect some data at the household level ${ }^{15-17}$. The fieldwork challenges highlighted are not unique to household surveys but are common to all surveys conducted in SSA.

Despite the large number of face-to-face interviews undertaken for health research surveys in SSA, there is a paucity of evidence in regard to the practicalities of fieldwork research in these settings ${ }^{18-20}$. This paper synthesises notes documented during fieldwork research as part of a doctoral thesis. It highlights challenges faced during the survey and strategies developed to overcome or reduce 
their impact on survey progress. The paper highlights lessons learnt during the research experience and suggests recommendations to address challenges faced.

\section{Method}

Description of survey project and fieldwork activities

A health survey namely, the 2010/2011 Centre for Health Economics Uganda HIV Survey (CUHS) was developed to explore the impact of additional social support for People Living With HIV/AIDS (PLWHA). The main objective was to establish whether individuals from a household that had PLWHA on anti-retroviral therapy (ART) and receiving additional social support, had better health and non-health outcomes compared to those from a household with PLWHA on ART only. The CUHS survey was cross-sectional and administered to 596 households from eleven districts and 34 ART clinics in Central Uganda from October 2010 to January 2011 (Figure 1).

Figure 1: List of health units that were covered for the survey

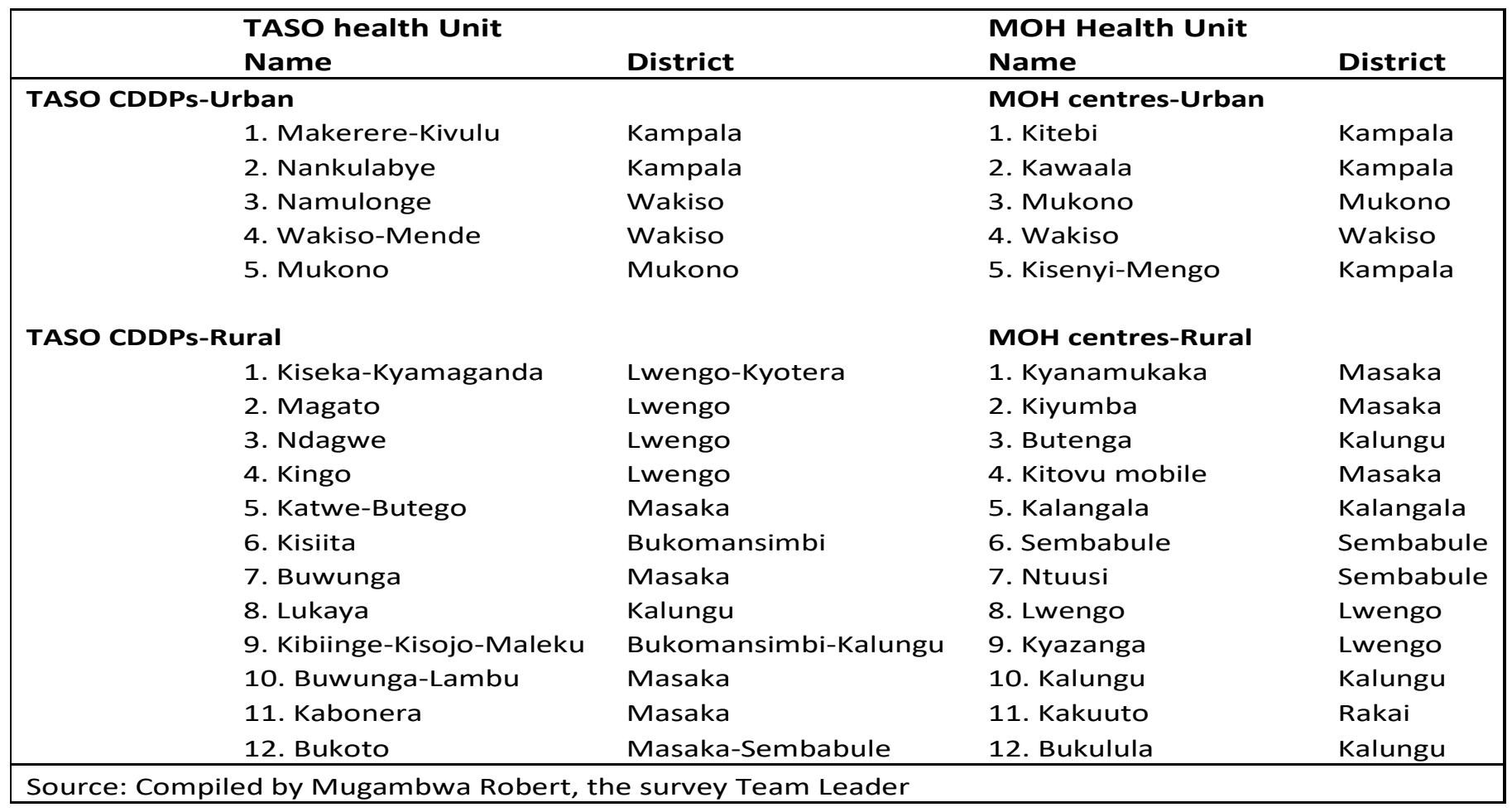

Households were selected if they had PLWHA served by one of two ART service providers specifically; Ministry of Health $(\mathrm{MOH})$ Uganda health clinics or The AIDS Support Organisation (TASO). MOH health clinics provided only ART while TASO provided social support in addition to ART. Control households surveyed had no known person living with HIV/AIDS and were selected based on geographical proximity to TASO and $\mathrm{MOH}$ households. The survey gathered information at the individual, household and health clinic level; further details are published elsewhere ${ }^{21}$.

The interviewers were highly trained researchers with a minimum qualification of a bachelor's degree, and formerly involved in similar household surveys by International Food Policy Research Institute (IFPRI) and
International Potato Centre in Uganda. This contrasts with other population based surveys where recruitment of highly qualified researchers is difficult for large-scale surveys ${ }^{22}$. The research team comprised of five research assistants/interviewers, one team leader and the $\mathrm{PhD}$ student researcher; of which three were female and four male. There were three additional research assistants trained as backup interviewers. Interviewers were trained by both the $\mathrm{PhD}$ student researcher and team leader. Training, pre-testing and revision period was over a period of fourteen days.

Household visits and interviews were carried out by research assistants while the survey team leader and $\mathrm{PhD}$ student researcher booked households to be interviewed each day. Local research guides who were clinic nurses, 
PLWHA volunteers, community ART support agents, TASO field officers or local council leaders provided guidance to local geography and transport modalities within the local area. Additional clinic-level administrative data were collected by the team leader after completion of the household survey. All participants provided a signed informed consent form and were compensated for their time after completion of the survey questionnaire.

The project was a collaboration between Monash University Centre for Health Economics, The AIDS Support Organisation (TASO) Uganda and Ministry of Health, Uganda. Monash University Human Research Ethics was the overall ethics team which approved the project after authorisation from all other participating organisations Project Number: CF10/1036-2010000543. Ethics application to Monash University Human Research Ethics Committee MUHREC was submitted in April 2010. Following submission, the investigators had a review interview with MUHREC at the beginning of June since the project was considered a high risk project. Conditional ethics approval was granted at the end of June 2010. The condition being receipt of approval letters from other participating organisations and Uganda National Council of Science and Technology (UNCST), which is the government approval body for research undertaken in Uganda. Final ethics approval from Monash was granted on 5th October 2010.

\section{Method for documenting survey challenges}

A reporting and feedback process was implemented at commencement of fieldwork to understand the challenges faced in undertaking interviews at the individual and household level, as well as respond to any emerging issues as they arose. Interviewers reported to the team leader and/or $\mathrm{PhD}$ researcher on a daily basis including the number and location of interviews undertaken each day, and any challenges faced during the fieldwork. The $\mathrm{PhD}$ researcher and team leader documented all matters raised and observed during fieldwork so as to monitor the progress of the interviews against the schedule and address any arising problems in a timely manner.

In addition, the research team held regular weekly meetings at the start of the survey and bi-weekly meetings later on to discuss experiences faced in the field including research obstacles or challenges. The meetings aimed at discussing possible solutions to urgent problems faced during fieldwork. They also discussed strategies for arising data collection concerns to improve and ensure data quality. This also involved discussions on coping and emotional challenges faced by the research team due to the detrimental impact of HIV/AIDS in combination with poverty on PLWHA households interviewed. The meeting information was also documented by the $\mathrm{PhD}$ researcher and team leader.

The process of daily reporting and regular meetings was familiar to the local research team who were experienced researchers and formerly engaged in similar fieldwork undertaken in SSA. However, in contrast to their previous work, this fieldwork was more sensitive given anonymity of respondent's HIV status to avoid potential stigma related to HIV/AIDS. Consequently, team meetings always discussed strategies to safeguard survey respondent HIV status and potential safety measures in case of unintended disclosure.

The data generated from written daily feedback and reports of meetings was analysed to determine the main challenges that researchers faced whilst undertaking fieldwork for face-to-face interviews particularly at the individual and household level. The data was explored to determine if consistent themes could be identified and grouped to provide insight for future fieldwork in SSA. Challenges faced are discussed in the results section while adoptive strategies are elaborated in the discussion.

\section{Results}

\section{Infrastructure and electrical power outages} Transport infrastructure and time of season

Past fieldwork experience made us aware of the weak road infrastructure in Uganda with the majority of rural roads as seasonal dirt roads ${ }^{23}$. These roads become seriously potholed and muddy especially during the rainy season, making travelling challenging and $\operatorname{slow}^{24,25}$. The survey was undertaken during the wet season which complicated mobility during the survey given poor road infrastructure.

\section{Poor data storage infrastructure}

The survey was designed to collect additional data through the clinic administrative data. Clinic level data was mainly in two formats, namely paper based for $\mathrm{MOH}$, and elec- 
tronic for TASO. The computerised record keeping system was quite effective in populating clients of interest using client numbers and eligibility criteria. In contrast, paper based records were challenging in terms of data consistency and quality. Several clinics lacked proper filing cabinets hence had poorly stored and disorganised files. This made it difficult and strenuous to extract the information needed. In one extreme case, a booking team of three people spent more than four hours to compile a list of 15 clients at one of the health centres.

\section{Poor energy and telecommunication infrastructure}

The poor condition of energy and telecommunication infrastructure ${ }^{26}$ presented drawbacks during the survey. Power outages were frequent making client specific data extraction from TASO difficult. Even when power was available, internet and modem inefficiencies presented further problems. In situations where paper files were used for $\mathrm{MOH}$ data generation, extraction of data after sunset was a challenge since having electricity for lighting was not always possible. In one such instance, the booking team had to use a phone torch for more than an hour to compile the list of clients.

Uganda's mobile network has improved in the past decade but rural areas still have very weak communication capacities $^{27}$. A great proportion of remote places covered during the survey had no network coverage making it difficult for the team to communicate especially in case of an emergency.

\section{Sampling challenges and access to individuals Rural dominance}

The CUHS was predominantly rural based leading to large geographical coverage due to sparsely populated rural areas. This challenged the project logistics in terms of high fuel costs, maintenance of the fieldwork vehicle and number of clients interviewed per day. This was further compounded by the survey's focus on PLWHA served by TASO and $\mathrm{MOH}$, which required reaching their households. Initially, our intention was to systematically cover clients from a single service provider each day but, the large geographic coverage made this impractical. As an alternative, we matched both $\mathrm{MOH}$ and TASO clients and covered all clients within the same geographical space irrespective of ART service provider. Movement from one household to another was problematic due to long distances between homes and inaccessibility of some homes by road hence, interviewers had to walk long distances to interview households. The distance problem was exacerbated by our having only one fieldwork vehicle which was required to drop research assistants for interviews in addition to undertaking booking of clients that were to be interviewed the following day.

In contrast, the main obstacle in the urban area was lack of time by clients to commit two hours to respond to the research questionnaire rather than embark on their work, especially for men involved in the trade business. Additionally, it was difficult to independently interview clients residing in slum areas due to overcrowding and interference from neighbours.

\section{Different structures and processes of health service provision}

The survey also involved multiple agencies that delivered similar ART services but with differing structures of service provision. This required non-identical approaches for booking clients for interviews. TASO provided services at the household level through Community Drug Distribution Points (CDDPs) which connect PLWHA at the grass roots. This avoided access issues for clients that were distantly located from TASO centres by bringing ART services nearer to the people who desperately needed them. Importantly, this made locating and accessing TASO households for interviews quite easy during the survey. In contrast, $\mathrm{MOH}$ health clinics service provision is at the clinic level. The absence of a formal framework to link with clients at the grassroots made it challenging to locate $\mathrm{MOH}$ households.

\section{Ethics approval and political stability Ethics application}

The investigators had anticipated the ethics application process to take a maximum of three months. However, the involvement of multiple agencies located in different countries with differing ethics procedures complicated the process. Approval of the project by the government body took considerable time due to bureaucracy and backlog of projects that needed approval. The process was further complicated because the project involved PLWHA leading to significant adjustments to ensure safety of research participants. Therefore, the entire ethics process required six months to complete, which was substantial time, especially for time restricted $\mathrm{PhD}$ research. 


\section{Political environment}

The survey commenced during the parliamentary and presidential campaigns of the 2011 elections in Uganda.

Surveys conducted during political campaigns require hard work to compete for the respondent's time. Campaigns in resource limited settings usually provide incentives to voters making it difficult for researchers to compete for clients' time to participate in their research.

\section{Safety and wellbeing of researchers}

Researchers had to move long distances between interviewed households, some of which were inaccessible by car, pausing safety concerns. Poor telecommunication also made it difficult to promptly contact the team leader in case of an emergency.

\section{Discussion}

Adaptive strategies: infrastructure and electrical power outages

The seasonal roads require a four wheel drive which can manage rainy weather. Delays due to power outages in the rural areas were reduced by using torches and kerosene lamps for lighting. Emergency torches were carried during fieldwork in case work ended after sunset. In the urban areas, a standby generator was hired to guard against power outages and ensure achievement of data entry timelines. Delays due to poor data can be overcome by populating clients' lists before fieldwork starts, similar to the DHS. Office recruitment avoids field manipulations $^{22}$.

Poor telecommunication made our initial emergency plan of telephoning fellow researchers infeasible. Consequently, the emergency plan was modified to use any local transport available to contact the local guide at a designated location. Set locations at the trading centres, health centres and sub-county offices were used as meeting points after completion of interviews.

\section{Adaptive strategies: sampling challenges and access to individuals}

The survey involved collaboration with stakeholders from ART health services and local community leaders to direct researchers to individual households. Local leaders are more familiar with the local area despite lack of maps or road labels to households. Integrating local leaders into research facilitated community collaboration and commitment, hence increasing participants' involvement.
To deal with urban challenges; our response was to start interviews at least an hour earlier 7:30am instead of 8:30 am and being flexible in conducting interviews either at home or workplace as preferred by the respondent. We made sure that interviews were at a secluded place where clients would feel confident to respond without worrying about their HIV status being discovered. Interview places were not isolated to ensure safety of the researcher.

\section{Adaptive strategies: ethics approval and political sta- bility}

Partnership between Monash University, TASO and $\mathrm{MOH}$ made the project more credible and acceptable though complicated ethics approval timing. Involvement of organisations in Uganda made communication by email infeasible therefore face to face meetings were organised. A key strategy is to contact the relevant personnel for research programmes to discover before hand the requirements for ethics approval and how long ethics processing would take.

We strategized to follow the campaign timetable to avoid booking clients on days where interviews coincided with political campaigns within the same locality. This aimed at maximising clients' research participation thereby improving survey coverage. It is advisable to embark on research outside political campaigns to avoid potential unrest which could endanger researchers and participants. This also guarantees presence of participants at their households for interviews rather than attending campaigns either due to payment for attendance or fear of ramifications of not attending. Tensions between researchers and the local political representatives competing over participants is also avoided.

\section{Adaptive strategies: safety and wellbeing of re- searchers}

The researchers were guided by the local community guide who was always aware of their interview schedule and location. The local guide was the first contact in case of an emergency and strategic emergency meeting locations at the clinic, trading centre shops or sub-county offices were established in each locality. The team had a first aid box in case of any minor accident but was limited by not having general insurance for the researchers.

\section{Strengths and limitations}

The major strength of the study is that documentation 
of the field experiences was undertaken on a regular basis during the survey period, rather than retrospectively once the survey had been completed. The study limitation is that it was not a planned focus group discussion on the topic but a compilation of notes by the team leader and $\mathrm{PhD}$ research student. This could lead to bias of notes written down based on who is taking them since standardisation wasn't applied. The study is also based on $\mathrm{PhD}$ research rather than a larger population-based health survey.

\section{Conclusion}

This paper highlights real-world challenges and adaptive strategies for undertaking a health survey in a resource limited setting like Uganda. Fieldwork is unpredictable with multilevel challenges faced throughout the survey process. Researchers need to quickly respond to fieldwork challenges to avoid delays and inefficiencies due to increasing survey operating costs. Complex research for instance on HIV/AIDS requires planning before hand. This is due to the rigorous ethics application given the sensitive nature of HIV/AIDS research and its potential stigma. The experiences highlighted in this paper give practical guide for future research in other SSA countries with similar challenges. Challenges are similar in both household and non-household based surveys but the impact may be greater for household-based surveys due to diverse coverage and distance travelled. This exposes researchers to inefficiencies due to road, energy and telecommunication infrastructure.

\section{Acknowledgements}

I acknowledge funding for the survey from the Centre for Health Economics, Monash University. I am grateful to "friends" from the Ministry of Health (MOH) Uganda and The AIDS Support Organisation (TASO) Uganda, who participated in the survey; and grateful to the $\mathrm{MOH}$ and TASO staff workers that assisted in linking us to the survey participants. I am indebted to the data collection team headed by Mugambwa Robert that worked tirelessly to collect the data. Thanks to the anonymous reviewers and Asoc Prof Jenny Watts for comments on an earlier draft.

\section{Conflict of interest}

There is no conflict of interest.

\section{References}

1. Collins F, Beaudet A, Draghia-Akli R, Gruss P, Savill J, Syrota A, et al. A database on global health research in Africa. The Lancet Global Health. 2013;12:e64-e5.

2. van Eijk AM, Hill J, Larsen DA, Webster J, Steketee RW, Eisele TP, et al. Coverage of intermittent preventive treatment and insecticide-treated nets for the control of malaria during pregnancy insub-Saharan Africa: a synthesis and meta-analysis of national survey data, 2009-11. The Lancet Infectious Diseases. 2013;1312:1029-42.

3. Moosa MR. Medicine in Africa: the problems and promises. The Lancet. 2013;3829902:1396-7.

4. Timæus I, Jasseh M. Adult mortality in sub-Saharan Africa: Evidence from demographic and health surveys. Demography. 2004;414:757-72. PubMed

5. García-Calleja JM, Gouws E, Ghys PD. National population based HIV prevalence surveys in sub-Saharan Africa: results and implications for HIV and AIDS estimates. Sexually Transmitted Infections. 2006; 82suppl 3:iii64-iii70.

6. Yager JE, Kadiyala S, Weiser SD. HIV/AIDS, Food Supplementation and Livelihood Programs in Uganda: A Way Forward? PLoS ONE. 2011;610: e26117. PubMed 7. ABS. About the Australian Health Survey Canberra: Australian Bureau of Statistics 2012 [cited 2014 January]. Available from: http://www.abs.gov.au/ausstats/abs@. nsf/Lookup/4364.0.55.001Chapter1202011-12.

8. Health and Social Care Information Centre. Health Survey for England: NHS Information Centre for Health and Social Care; 2011 [cited 2014 January]. Available from: http:/ /data.gov.uk/dataset/health_survey_for_england.

9. CDC. National Center for Health Statistics. Monitoring the Nations Health Atlanta, USA: Centers for Disease Control and Prevention 2014 [cited 2014 January]. Available from: http://www.cdc.gov/nchs/index.htm.

10. Farrell G. Survey of ICT and Education in Africa: Uganda Country Report World Bank, Washington DC; 2007 [cited 2014 January]. Available from: https://openknowledge.worldbank.org/handle/10986/10655

11. Nanka-Bruce O. The socio economic drivers of rural electrification in Sub-Saharan Africa Guildford: University of Surrey; 2010 [cited 2013 December]. Available from: http://www.seec.surrey.ac.uk/Research/SEEDS/ SEEDS128.pdf.

12. UBOS. Uganda National Household Survey: 2009/2010 Socio-Economic Module Kampala: Uganda Bureau of Statistics UBOS; 2010 [cited 2013 December]. 
22]. Available from: http://www.ubos.org/UNHS0910/ unhs200910.pdf.

13. Verner D. What Factors Influence World Literacy? Is Africa Different? : World Bank; 2005 [cited 2014 Jan]. Available from: http://elibrary.worldbank.org/doi/ book/10.1596/1813-9450-3496.

14. UNICEF. Uganda Statistics 2014 [cited 2014 January]. Available from: http://www.unicef.org/infobycountry/uganda_statistics.html\#103.

15. Sofaer N, Kapiriri L, Atuyambe LM, Otolok-Tanga E, Norheim OF. Is the selection of patients for anti-retroviral treatment in Uganda fair?: A qualitative study. Health Policy. 2009;911:33-42. PubMed

16. Gilbert L, Walker L. "They ARVs are my life, without them I'm nothing"- experiences of patients attending a HIV/AIDS clinic in Johannesburg, South Africa. Health \& Place. 2009;154:1123-9. PubMed

17. Asamoah-Odei E, Calleja JMG, Boerma JT. HIV prevalence and trends in sub-Saharan Africa: no decline and large subregional differences. Lancet. 2004;3649428:35 -40. PubMed

18. Casale MAJ, Flicker S, Nixon SA. Fieldwork Challenges: Lessons Learned From a North-South Public Health Research Partnership. Health Promotion Practice. 2011;125:734-43.

19. Casale M, Lane T, Sello L, Kuo C, Cluver L. Conducting health survey research in a deep rural South African community: challenges and adaptive strategies. Health Research Policy and Systems. 2013;111:14.

20. Mathee A, Harpham T, Naicker N, Barnes B, Plagerson S, Feit M, et al. Overcoming fieldwork challenges in urban health research in developing countries: a research note. International Journal of Social Research Methodology. 2009;132:171-8.
21. Abimanyi-Ochom J, Lorgelly P, Hollingsworth B, Inder B. Does social support in addition to ART make a difference? Comparison of households with TASO and MOH PLWHA in Central Uganda. AIDS Care: Psychological and Socio-medical Aspects of AIDS/HIV. 2013;255:61926.

22. Vaessen M, Thiam M, Lê T. The Demographic and Health Surveys. 2005. In: Household sample surveys in developing and transition countries [Internet]. New York: United Nations Publication. Available from: http://millenniumindicators.un.org/unsd/hhsurveys/pdf/Chapter_22.pdf.

23. Van Campenhout B, Pauw K, Minot N. The impact of food prices shocks in Uganda: First-order versus longrun effects Washington DC.: International Food Policy Research Institute; 2013 [cited 2014 Jan]. Available from: http://www.ifpri.org/sites/default/files/publications/ ifpridp01284.pdf.

24. Gollin D, Rogerson R. Agriculture, Roads, and Economic Development in Uganda 2010. Available from: http://www.nber.org/papers/w15863.

25. Kulabako F. Tourism players want government to improve Uganda's road network Kampala: Daily Monitor Newspaper; 2013 [cited 2014 Jan]. Available from: http://www.monitor.co.ug/News/National/Tourism-players-want-govt-to-improve-Uganda-s-road-network/-/688334/1864216/-/prl2uk/-/index.html.

26. The World Bank. Africs's Infrastructure: A Time for Transformation Washinton DC: The international Bank for Reconstruction and Developement/The World Bank, 2010.

27. International Telecommunication Union. The Internet in an African LDC: Uganda Case Study. 2001. 